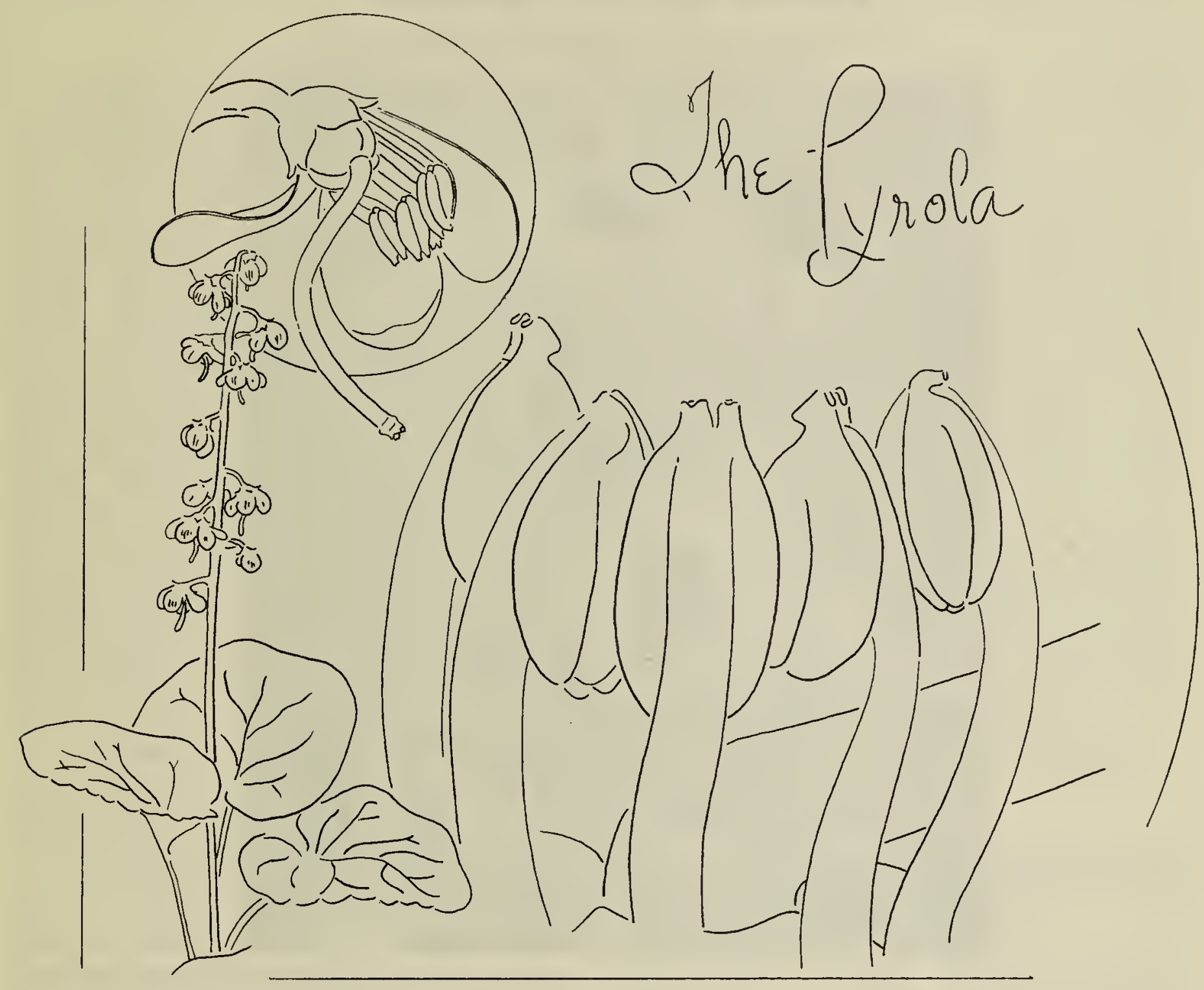

\title{
The Pyrola
}

R. B. WILLEMS, Edenwold, Sask.

The fragrant and dainty pyrola thrives in the twilight of our poplar woods, where only a few long rays of light reach down to touch the potpourri of last year's decaying leaves. Numerous rosy cup-shaped flowers, nodding from an erect but slender stalk, make this plant especially attractive.

If the raceme of cup-shaped flowers nodding in a stray breeze is charming, the individual blossom is as beautiful under close inspection. The petals are pink, blushing towards the edge; even the green recurved sepals show traces of pink. The long protruding style, which hangs well below the slightly imbricated petals, is pale green. For sheer beauty, the throng of stamens is a delight to see; the filaments, flat and quite wide, are delicate pink suspending dark anthers responsible in due time for a shower of pollen.

The thick glossy leaves which grow in a cluster at the base of the plant are somewhat pear-shaped in some species and hence, account for the name, pyrola - little pear. While most flowering plants are with us for only a very short season, the pyrola graces us with its presence for all seasons, retaining its verdure through frost and snow - the pyrola is a perennial with evergreen leaves. As this sturdy little plant subsists through summer and winter, it is a reminder of the cycle of the seasons:

While the earth remaineth, seedtime and harvest, and cold and heat, and summer and winter, and day and night shall not cease. 